\title{
Non-descent vaginal hysterectomy surgery associated with less complications and good prognosis
}

\author{
Pranita O Somani', Priyanka Singh ${ }^{2}$, Mangala Shinde ${ }^{3}$ \\ ${ }^{1}$ Assistant Professor, ${ }^{3}$ Professor and Head, Department of Obstetrics and Gynecology, Government Medical College, Latur, \\ Maharashtra, ${ }^{2}$ Gynecology Consultant, Department of Obstetrics and Gynecology, Krishna Hospital, Jodhpur, Rajasthan, India
}

Background: Removal of the uterus through vagina when performed in a case without uterine descent or prolapse is known as "non-descent vaginal hysterectomy" or NDVH. Vaginal route is preferred as compared to laparoscopic and abdominal methods. The advantages of vaginal hysterectomy being fewer complications, less post-operative stay, cost effective, and useful in bulky uterus. Aims and Objectives: The aims of the study were as follows: (1) To study the intraoperative and post-operative complications encountered during NDVH and their management. (2) To assess the intraoperative blood loss, the operative time, and postoperative hospital stay. (3) To study and check the feasibility of vaginal route as the primary route for all hysterectomies in the absence of uterine prolapse. Materials and Methods: A total of 50 patients were included in the study. Detailed history was taken including obstetric history and menstrual history and clinical examination was performed. After taking written, informed consent and doing proper pre-operative preparation, the patient was posted for NDVH. Post-operative complications were noted. Patients were asked to come for followup after 15 days. Results: In $92 \%$ of cases operated, no intraoperative complications were found suggesting low morbidity associated with the procedure. Hemorrhage requiring blood transfusion was found in $4 \%$ of cases. Average operative time was $61.2 \pm 27.89$ min, average blood loss was $170 \pm 81.44 \mathrm{ml}$, and average hospital stay was $5.94 \pm 4.95$ days. On histopathological examination, $40 \%$ were having leiomyoma and dysfunctional uterine bleeding was seen in $22 \%$ of cases. Pain was the most common complication seen in $30 \%$ of cases while vaginal discharge was seen in just $4 \%$ of cases. About $80 \%$ of patients were discharged on post-operative day 5 . Conclusion: In $92 \%$ of NDVH cases, no intraoperative complications were found suggesting low morbidity associated with the procedure. The post-operative hospital stay was restricted to 5 days in $80 \%$ of cases which indicates early discharge of the patient. Post-operative complications such as vaginal discharge and fever were seen only in $4 \%$ of cases. NDVH should, therefore, be considered as the primary route for all hysterectomies unless contraindicated in the absence of prolapse.

Key words: Complications; Hemorrhage; NDVH; Post-operative stay
Access this article online

Website:

http://nepjol.info/index.php/AJMS

DOI: 10.3126/ajms.v13i1.40294

E-ISSN: 2091-0576

P-ISSN: 2467-9100

Copyright (c) 2022 Asian Journal of Medical Sciences

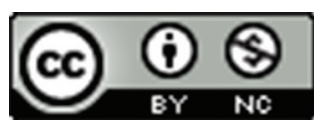

This work is licensed under a Creative Commons Attribution-NonCommercial 4.0 International License.

\section{INTRODUCTION}

Hysterectomy is a frequently performed gynecologic and obstetric procedure worldwide, second only to cesarean delivery. ${ }^{1}$ It is extremely safe operation, with an average visceral damage rate being $0.5-2 \%$ and mortality rate of $0.5-2 / 1000 .^{2}$ Hysterectomy can be minimally invasive with procedures such as non-descent vaginal hysterectomy
(NDVH), laparoscopically-assisted vaginal hysterectomy (LAVH), and total laparoscopic hysterectomy. Majority of hysterectomies are performed for benign reasons. ${ }^{3}$ Vaginal route should be preferred wherever possible as it has less morbidity, lesser hospital stay, and better patient satisfaction. The main indication for vaginal hysterectomy is uterovaginal prolapse and indications such as enlarged uterus and menstrual abnormalities are treated mainly by abdominal route. ${ }^{4}$ Since 
1990, LAVH has developed and gained acceptance. Now, various techniques have been developed to perform NDVH successfully in patients with dense adhesions such as posterioranterior approach and $\mathrm{h} / \mathrm{o}$ previous pelvic surgery with entry through the lateral approach. Furthermore, studies such as the Collaborative Review of Sterilization study, ${ }^{5}$ Ottosen et al., ${ }^{6}$ and Taylor et al. ${ }^{7}$ have shown vaginal hysterectomy to be a valid alternative to the abdominal approach with fewer complications, shorter recovery period, and hospital stay. In addition, studies also suggest that vaginal hysterectomy can also be performed successfully even in women with an enlarged uterus, nulliparity, or history of pelvic surgery and the need for oophorectomy should not be considered a contraindication..$^{5-7}$ In the interest of the patient, every gynecologist must be convinced that vaginal route is the best approach, strengthens his/her findings clinically, by ultrasonography and examination under anesthesia, and finally starts to attempt NDVH on gradually increasing size of uterus.

\section{Aims and objectives}

The aims of the study were as follows:

1. To study the intraoperative and post-operative complications encountered during NDVH and their management.

2. To assess the intraoperative blood loss, the operative time, and post-operative hospital stay.

3. To study and check the feasibility of vaginal route as the primary route for all hysterectomies in the absence of uterine prolapse.

\section{MATERIALS AND METHODS}

Type of study

This was a prospective observational study.

\section{Place of study}

The study was conducted at the Department of OBGY, Dr. Vaishampayan Memorial Government Medical College, Solapur.

\section{Study duration}

The study duration was from November 1, 2013, to October 31, 2015 (2 years).

\section{Sample size}

Fifty.

\section{Inclusion criteria}

Patients giving informed consent were included in the study.

\section{Exclusion criteria}

Endometriosis, uterine prolapse, immobility of uterus, genital malignancy, size of uterus $>18$ weeks, and ovarian tumors were excluded from the study.

\section{Procedure}

This study was pre-approved by the Institutional Ethics Committee for the final permission. Patient's age, parity, socioeconomic status, marital status, present history, and past history were taken. Gynecological examination included per speculum examination, per vaginal examination for assessing size of the uterus, mobility of the uterus, assessment of the space available around the uterus, descent of the uterus, and the presence of adnexal pathology was looked for and special mention was made if the patient had undergone any previous abdominal/pelvic surgery or LSCS. Pelvic ultrasonography was done to rule out gross adnexal pathology, for the assessment of uterine size and the site of fibroids in case there were any. Dilatation and curettage were done in almost all patients before posting the patient for NDVH to aid the diagnosis and to rule out malignancy. Cervical biopsy was done in patients based on their complaints and clinical examination findings as and when required. A proper written and informed consent was taken from all patients and their relatives after explaining the procedure. Special consent for conversion to abdominal hysterectomy if needed and chances of bladder and bowel injury was taken. After proper pre-operative preparation, the patient was posted for NDVH. A good bowel preparation was given 1 day before to help good exposure and avoid bowel injury. Injectable antibiotic was given prophylactically to all women $1 \mathrm{~h}$ before operation began. The vagina was infiltrated at its junction with the cervix with $10-30 \mathrm{ml}$ normal saline. A circumferential incision was made at the junction of cervix and vagina. Anterior and posterior pouch was opened. After ligating bilateral uterosacral and Mackenrodt's ligaments, bilateral uterine vessels were ligated. The next step of hysterectomy depended on the size of the uterine mass and included use of various debulking methods such as bisection, myomectomy, or a combination of these if required. The uterus was removed after clamping the round ligaments and utero-ovarian ligaments. After the delivery of uterus, the tubes and adnexa were removed where necessary by ligating the infundibulopelvic ligament. Hemostasis was achieved and confirmed. The peritoneal cavity was closed and the vault is suspended and closed. Intraoperative complications were noted if any. Operative time was calculated from the beginning of the incision at the cervicovaginal junction to the closure of the vaginal vault. Blood loss was calculated by noting the number of mops used during the procedure and the amount of blood sucked in the suction bottle. On an average, one fully soaked mop corresponds to $80 \mathrm{ml}$ of blood. Post-operative catheterization with Foley's catheter was done in all patients, which was removed in most of the cases on post-operative day 1. Removed specimen of uterus with cervix with/without adnexa was sent for histopathological examination. Post-operative complications such as fever, UTI, vaginal discharge, 
vaginal bleeding, diarrhea, and pain were noted. Pain in post-operative period was considered as morbidity when it did not subside with regular dosage of analgesics. Postoperative hospital stay was calculated from the day of operation to the day of discharge. All the patients were asked to follow up after 15 days.

\section{RESULTS}

Among the 50 patients, 49 patients successfully underwent NDVH. In one patient, the surgery was converted to abdominal hysterectomy due to greater transverse diameter of the uterus and limited descent.

Out of 50 patients, $52 \%$ belonged to $41-50$ years age group and $40 \%$ were from 31 to 40 years of age group. About 98\% were married, $88 \%$ were menstruating, and $12 \%$ were menopausal. Multiparity was favorable factor for NDVH. Menorrhagia, dysmenorrhea, and chronic abdominal pain were the main symptoms in $72 \%, 18 \%$, and $16 \%$ of cases, respectively. About $78 \%$ had previously undergone tubectomy. On ultrasonography, normal sized uterus was found in $34 \%$, anterior wall fibroid was next common finding found in $32 \%$. Uterine fibroid was the most common indication for surgery.

In our study, as per Table 1, one patient had injury to the rectum while opening the posterior pouch. The patient was nulliparous. NDVH was continued and uterus was removed vaginally. After this, laparotomy was performed and a rent of $5 \mathrm{~cm}$ was noted in the rectum. This rent was repaired by primary closure and colostomy was done. In one patient, NDVH was converted to total abdominal hysterectomy (TAH). This patient had multiple fibroids and the transverse diameter of uterus was more so it could not be removed vaginally. Blood transfusion was required in two patients due to increased intraoperative blood loss.

As per Figure 1, unexplained fever was seen in 2 patients (4\%) on post-operative day 2 which subsided without any significant complications and intervention. UTI was observed in 10\% patients postoperatively. It resolved after a course of antibiotics. Diarrhea was observed on day 3 in 3 patients $(6 \%)$. It was most probably due to the close proximity of rectum during NDVH causing irritation. Pain and backache were complaint of $30 \%$ of patients on post-operative day 3 . The pain subsided with analgesics. Vaginal discharge was seen in $4 \%$ of patients on day 3. It resolved with antibiotics.

As per Table 2, from among the 50 cases studied, the average operative time was $61.2 \pm 27.89 \mathrm{~min}$, the average intraoperative blood loss was $170 \pm 81.44 \mathrm{ml}$ and the average hospital stay of the patients was $5.94 \pm$ 4.95 days. In this study, it was observed that one patient had intraoperative bowel injury which increased the time duration of operation, the amount of blood loss, and the hospital stay in this patient. When the surgical parameters were assessed baring this patient, the following results were observed.

From Table 3, it is observed that as the operative time in NDVH increases, the amount of intraoperative blood loss also increases. Thus, blood loss is highly, statistically and significantly $(\mathrm{P}<0.001)$ dependent on the operative time for surgery. Furthermore, the operative time and the amount of intraoperative blood loss, both are related to the size of uterus, that is, as the uterine size increases, operative time and intraoperative blood loss increase.

As per Figure 2, majority of patients were discharged on postoperative day $5(80 \%)$. Out of the 50 cases studied, $6(12 \%)$ patients were discharged on post-operative day 6 . The cause was UTI and diarrhea. Out of the 50 cases studied, 4 (8\%) patients were discharged on post-operative day 7 and after that due to the intraoperative complications prolonging their stay.

With reference to above Table 4, the most common finding on histopathological examination of the specimen was

\begin{tabular}{lcc} 
Table 1: Intraoperative complications & \\
\hline Intraoperative complications & $\begin{array}{c}\text { Number } \\
\text { of patients }\end{array}$ & Percentage \\
\hline Bowel injury (laparotomy) & 01 & 2 \\
Hemorrhage requiring transfusion & 02 & 4 \\
Conversion to Tah & 01 & 2 \\
None & 46 & 92 \\
Total & 50 & 100 \\
\hline
\end{tabular}

TAH: Total abdominal hysterectomy

\begin{tabular}{lc} 
Table 2: Surgical parameters & \\
\hline Parameters & Mean \pm SD \\
\hline Average operative time & $61.2 \pm 27.89 \mathrm{~min}$ \\
Average blood loss & $170 \pm 81.44 \mathrm{ml}$ \\
Average hospital stay & $5.94 \pm 4.95$ Days \\
\hline
\end{tabular}

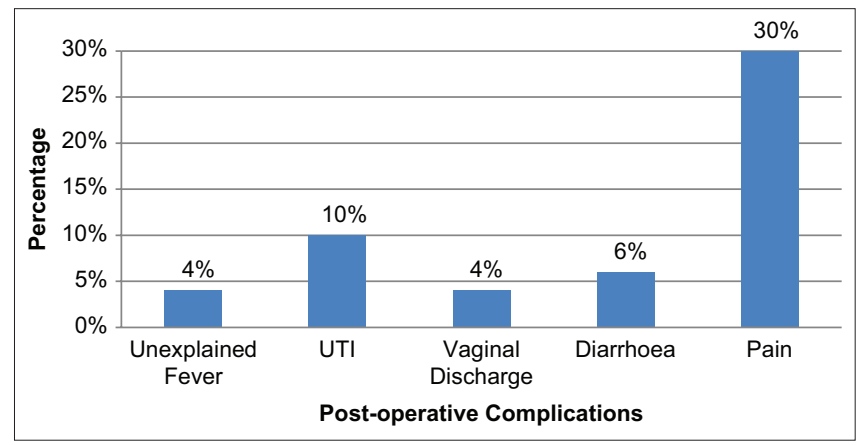

Figure 1: Post-operative complications 
Table 3: Surgical parameters (with average calculated)

\begin{tabular}{|c|c|c|c|}
\hline & $\begin{array}{l}\text { Average operative time (minutes) } \\
\qquad(\mathrm{N}=49)\end{array}$ & $\begin{array}{l}\text { Average blood loss }(\mathrm{ml}) \\
(\mathrm{N}=49)\end{array}$ & $\begin{array}{l}\text { Average hospital stay (days) } \\
\qquad(\mathrm{N}=49)\end{array}$ \\
\hline Mean士SD & $57.55 \pm 10.71$ & $161.22 \pm 53.29$ & $5.24 \pm 0.56$ \\
\hline r value & \multicolumn{2}{|c|}{0.65} & - \\
\hline t-value & \multicolumn{2}{|c|}{5.86} & - \\
\hline$P$ value & \multicolumn{2}{|c|}{$<0.001$} & - \\
\hline
\end{tabular}

\begin{tabular}{lcc} 
Table 4: Histopathology report & \\
\hline Finding on HPR & $\begin{array}{c}\text { Number of } \\
\text { patients }\end{array}$ & Percentage \\
\hline Leiomyoma & 20 & 40 \\
Adenomyosis & 05 & 10 \\
Leiomyoma with adenomyosis & 08 & 16 \\
Endometrial hyperplasia & 06 & 12 \\
No significant pathology/DUB & 11 & 22 \\
Total & 50 & 100 \\
\hline
\end{tabular}

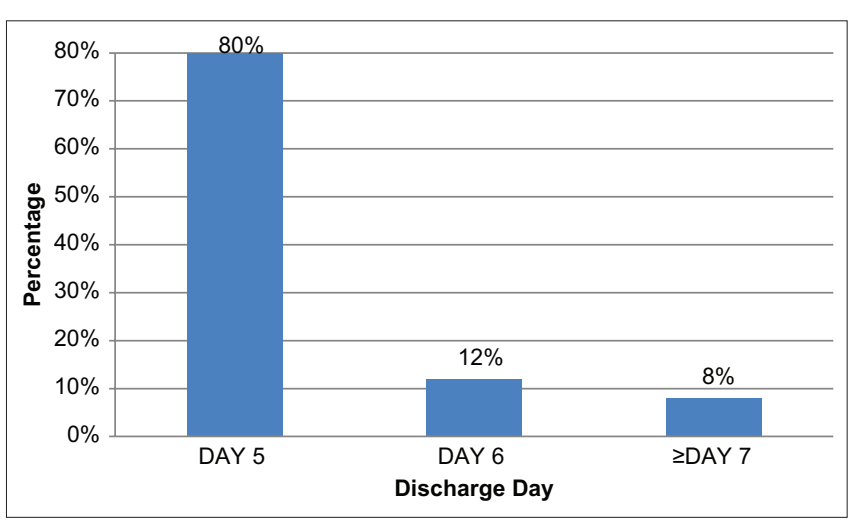

Figure 2: Post-operative discharge day

leiomyoma (40\%). The second most common finding was DUB (22\%). Adenomyosis was seen in $10 \%$ of the patients on histopathology examination. It was observed that adenomyosis was under diagnosed clinically. In this study, it was observed that in all the patients operated for NDVH, there were no mortality and minimal morbidity.

\section{DISCUSSION}

In our study, in 1 patient (2\%), NDVH had to be converted to TAH. One patient had bowel injury and laparotomy had to be done. Bowel injury was due to difficulty in opening the pouch of Douglas in a nulliparous patient. Blood transfusion was required in $4 \%$ of patients due to intraoperative blood loss. Similar results were found in studies conducted by Saha et al., ${ }^{8}$ (2012), Begum et al., ${ }^{9}$ (2014), Chandana et al., ${ }^{10}$ (2015) and Pradeep et al., ${ }^{11}$ (2015).

In our study, intraoperative bowel injury was seen in one patient but bladder injury was not found. Bladder injury during vaginal hysterectomy has been variously reported between 0.5 and $1.6 \%$. Unger reported an incidence of $2.8 \%$ in the past LSCS group versus $1.6 \%$ in those without LSCS. ${ }^{12}$ Sheth reported a very low incidence of bladder injury of $0.1 \%{ }^{13}$

The rate of conversion of NDVH to TAH was reported to be as high as $14 \%$ in study done by Saha et al., ${ }^{8} 5.38 \%$ in study by Pradeep et al., ${ }^{11}$ and 3.4\% in study by Singh and Bansal. ${ }^{14}$

With increasing expertise, the risk of intraoperative complications decreases.

Intraoperative bowel injury in study by Begum et al., ${ }^{9}$ (2014) was $0.79 \%$.

Post-operative complications observed in our study were due to unexplained fever, UTI, pain, vaginal discharge, and diarrhea. None of these complications required specific interventions. They resolved with regular treatment without any sequelae.

Similar results were found in other case series conducted by Kumar and Antony ${ }^{15}$ (2004), Bhadra et al., ${ }^{16}(2011)$, Saha et al., ${ }^{8}$ (2012), Mehta et al., ${ }^{17}$ (2014), Doppa et al., ${ }^{18}$ (2014), Chandana et al., ${ }^{10}$ (2014), and Mehla et al., ${ }^{19}$ (2015). Pain was the most common post-operative complication in studies by Saha et al., ${ }^{8}$ (2012) and Mehla et al., ${ }^{19}$ (2015). In a study by Pradeep et al., ${ }^{11}$ (2015), $10.83 \%$ of patients had post-operative pyrexia, $7.5 \%$ had UTI, and $2.5 \%$ had vaginal discharge.

NDVH is almost an entirely extra-peritoneal operation. The peritoneum is opened to a very little extent and minimal handling of intestines is required. Hence, post-operative ileus is much less common in NDVH and so oral intake and mobilization are earlier, therefore reducing the hospital stay. Furthermore, the morbidity of abdominal incision is avoided. Post-operative complications of NDVH are minimal.

In the present study, average operating time was $61.2 \pm$ $27.89 \mathrm{~min}$, average blood loss was $170 \pm 81.44 \mathrm{ml}$, and average hospital stay was $5.94 \pm 4.95$ days.

The operative time was more in earlier phase of learning curve. It was also related to the size of the uterus. Increased 
uterine size was associated with increased operative time. Similarly, large size uteri were found to be associated with increased blood loss. Blood loss and operative time were found to be directly proportional. Increased operative time associated with increased blood loss. Increased operative time was mostly due to intraoperative complications and bigger size of the uteri requiring morcellation. Similar results were seen in a study by Kumar and Antony ${ }^{15}$ (2004).

Average hospital stay in our study was increased due to prolonged hospital stay of one patient due to intraoperative bowel injury.

These parameters were comparable to surgical parameters in other studies conducted by Dewan et al., ${ }^{20}$ (2004), Bhadra et al., ${ }^{16}$ (2011), Saha et al., ${ }^{8}$ (2012), Bandhyopadhyay and $\mathrm{Pal}^{21}$ (2012), Mehla et al., ${ }^{19}$ (2015) and Pradeep et al., ${ }^{11}$ (2015).

The average hospital stay in our study was more as compared to studies by Dewan et al., ${ }^{20}$ (2004), Bhadra et al., ${ }^{16}$ (2011), Saha et al., ${ }^{8}$ (2012), Mehla et al., ${ }^{19}$ (2015) and Pradeep et al., ${ }^{11}$ (2015). However, it was comparable to other studies by Bandhyopadhyay and $\mathrm{Pal}^{21}$ (2012), Doppa et al., ${ }^{18}$ (2014) and Datti et al.,22 (2012).

In our study, $80 \%$ of the patients were discharged on postoperative day 5. Similar findings were found in a study by Pradeep et al., ${ }^{11}$ (2015). In this study, majority of patients were discharged on post-operative day $<5$.

\section{Limitations of the study}

Patients with large sized uterus $>18$ weeks size, large uteri with more transverse diameter, reduced mobility of uterus due to adhesions and endometriosiswere not included in this study. So the operative difficulties in such cases could not be assessed.

\section{CONCLUSION}

In $92 \%$ of NDVH cases, no intraoperative complications were found suggesting low morbidity associated with the procedure. The post-operative hospital stay was up to 5 days in $80 \%$ of cases which indicate early discharge and fast recovery of the patient. Post-operative complications such as vaginal discharge and fever were seen only in $4 \%$ of cases. Hence, NDVH can be successfully performed in benign uterine conditions. NDVH can be accomplished with less operative time, minimal blood loss, and minimal intraoperative complications. Post-operative complications following NDVH are minimal and subside without sequelae. NDVH should, therefore, be considered as the primary route for all hysterectomies unless contraindicated in the absence of prolapse.

\section{ACKNOWLEDGMENT}

We are thankful to the department of Obstetrics \& Gynecology at Dr. VMGMC, Solapur for their constant support and encouragement throughout the study. We are also thankful to the Dean, Dr. VMGMC, Solapur for their support and guidance in this study.

\section{REFERENCES}

1. Wilcox L, Koonin L, Pokras R, Strauss L, Xia Z and Peterson H. Hysterectomy in the United States, 1988-90. Obstet Gynecol. 1994;83:549-555.

https://doi.org/10.1097/00006250-199404000-00011

2. Manyonda I. Hysterectomy for benign gynaecological disease. Curr Obstet Gynaecol. 2003;13(3):159-165. https://doi.org/10.1016/S0957-5847(03)00008-8

3. Mittal P, Andiliya A, Bansiwal R, Jyotsna $S$ and Sunita $S$. Enlarged uterus through a natural orifice: Worth an effort? A randomized controlled trial. Int J Reprod Contracept Obstet Gynecol. 2014;3(4):1076-1081.

https://doi.org/10.5455/2320-1770.jijcog20141239

4. Amirikia $\mathrm{H}$ and Evans $\mathrm{T}$. Ten year review of hysterectomies. Am J Obstet Gynecol. 1979;134(4):431-437.

https://doi.org/10.1016/S0002-9378(16)33085-X

5. Dicker RC, Greenspan JR, Scally MJ, Layde PM, Ory HW, Maze JM et al. Complications of abdominal and vaginal hysterectomy among women of reproductive age in the United States. Am J Obstet Gynecol. 1982;144:841-848. https://doi.org/10.1016/0002-9378(82)90362-3

6. Ottosen $C$, Lingman $G$ and Ottosen L. Three methods for hysterectomy: A randomised, prospective study of short-term outcome. BJOG. 2001;107(11):1380-1385.

https://doi.org/10.1111/j.1471-0528.2000.tb11652.x

7. Taylor S, Romero A, Kammerer-Doak D, Qualls $C$ and Rogers $R$. Abdominal Hysterectomy for enlarged myomatous uterus compared with vaginal hysterectomy with morcellation. Am J Obstet Gynecol. 2003;189(6):1579-1582. https://doi.org/10.1016/S0002-9378(03)00942-6

8. Saha R, Shreshtha N, Bajracharya J and Padhye S. Nondescent vaginal hysterectomy: Safety and feasibility. NJOG. 2012;7(2):14-16. https://doi.org/10.3126/njog.v7i2.11134

9. Begum S, Akhtar R, Barua S and Ferdous J. A cross-sectional descriptive study on non-descent vaginal hysterectomy. Chittagram Maa-O-Shishu Hosp Med Coll J. 2014;13(1):1-4. https://doi.org/10.3329/cmoshmcj.v13i1.19411

10. Chandana $C$, Shreedhar V and Shah T. Non-descent vaginal hysterectomy for benign gynecological disease-a prospective study. J Evid Based Med Healthc. 2014;1(8):827-833. https://doi.org/10.18410/jebmh/2014/125

11. Pradeep S, Beeresh C, Krishna L, Vimala K, Shailaja N, Pallavi P, et al. Non-descent vaginal hysterectomy: Analysis of 120 cases. J Evid Based Med Healthc. 2015;2(32):4729-4735. https://doi.org/10.18410/jebmh/2015/664

12. Unger JB and Meeks GR. Vaginal hysterectomy in women with history of previous cesarean delivery. Am J Obstet Gynecol. 1998;179(6):1473-1578. https://doi.org/10.1016/S0002-9378(98)70011-0 
13. Sheth SS. The scope of vaginal hysterectomy. Eur J Obstet Gynecol Reprod Biol. 2004;115(2):224-230.

https://doi.org/10.1016/j.ejogrb.2004.02.016

14. Singh $A$ and Bansal S. Vaginal hysterectomy for non-prolapsed uterus. J Obstet Gynecol India. 2006;56(2):152-155.

15. Kumar $S$ and Antony ZK. Vaginal hysterectomy for benign nonprolapsed uterus-initial experience. J Obstet Gynecol India. 2004;54(2):60-63.

16. Bhadra B, Chaudhary AP, Tolasaria A and Nupur N. Non descent vaginal hysterectomy: Personal experience in158 cases. Al Ameen J Med Sci. 2011;4(1)23-27.

17. Mehta S, Trivedi $Y$ and Bhalodia P. Role of non-descent vaginal hysterectomy in advancing gynecological practice. NHL J Med Sci. 2014;3(1):55-58.

18. Doppa G, Gowder R and Rao T. Vaginal removal of non-prolapsed uterus with benign pathology. Indian Med Gazette. 2014;148(4):123-128.

19. Mehla S, Chutani N and Gupta M. Non-descent vaginal hysterectomy: Personal experience of 105 cases. Int J Reprod Contracept Obstet Gynecol. 2015;4(1):61-65. https://doi.org/10.5455/2320-1770.ijrcog20150212

20. Dewan R, Agrawal S, Minocha M, Sen B and Soumendra K. Non descent vaginal hysterectomy-an experience. J Obstet Gynecol India. 2004;54(4):376-378.

21. Bandhyopadhyay S and Pal M. Non descent vaginal hysterectomyanalysis of 100 cases. Asian J Med Sci. 2012;3(1):1-5. https://doi.org/10.3126/ajms.v3i1.4471

22. Datti S, Dharma $V$ and Sudha R. Vaginal approach for hysterectomy in benign conditions of uterus at rural health setting. Int J Basic Appl Med Sci. 2012;2(3):209-213.

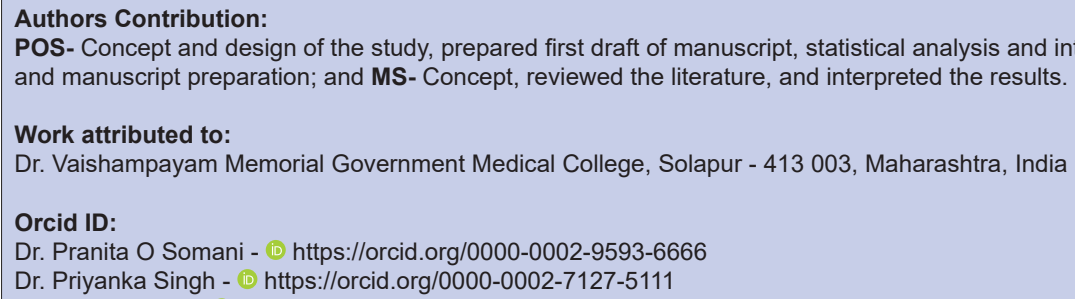

